http://dx.doi.org/10.18232/alhe.970

Artículos

\title{
Familias capitulares y poder político en el Cabildo de Buenos Aires, 1776-1810
}

\section{Capitular Families and Political Power in the Cabildo of Buenos Aires, 1776-1810}

\author{
Laura C. del Valle ${ }^{1, *}$ (D) 0000-0003-1735-6137 \\ Juan M. C. Larrosa ${ }^{1,2}$ (D) 0000-0002-0102-9994
}

${ }^{1}$ Universidad Nacional del Sur, Departamento de Humanidades, Buenos Aires, Argentina.

${ }^{2}$ Instituto de Investigaciones Económicas y Sociales del Sur, Departamento de Economía, Buenos Aires, Argentina.

*Correspondencia: jlarrosa@uns.edu.ar

Resumen. Este artículo analiza la relación entre las nominaciones postuladas para acceder a cargos en el cabildo de Buenos Aires, entre 1776 y 1810 y la posición relativa de las familias concejiles en la red social capitular. En el análisis de las redes sociales encontramos evidencia estadística que corrobora el vínculo entre el poder político y el lugar que ocupan las familias capitulares. De este modo, podemos localizar las familias influyentes y su probabilidad de acceso a cargos destacados.

Palabras clave: familia; poder político; análisis de redes sociales; Cabildo.

Abstract. This article analyzes the relationship between the nominations made for seats in the Cabildo of Buenos Aires between 1776 and 1810, and the relative position of political families in the capitular social network. We found statistical evidence that corroborates the relationship between political power and the position of capitular families using social network analysis.

CÓMO CITAR: Valle, L. C. y Larrosa, J. M. C. (2019). Familias capitulares y poder político en el Cabildo de Buenos Aires, 17761810. América Latina en la Historia Económica, 26(2), e970. DOI: 10.18232/alhe.970 
Key words: families; political power; network analysis; Cabildo.

JEL: N16; N46; D73; L14.

Recibido: 10 de marzo de 2018.

Aceptado: 31 de agosto de 2018.

Publicado: 13 de febrero de 2019.

\section{INTRODUCCIÓN}

El poder político puede erigirse y mantenerse a través de los lazos sociales. Las relaciones bien afianzadas pueden generar mutua confianza entre individuos, que deriva en compromisos y alianzas. Los lazos familiares facilitan este proceso en entornos de fuerte interacción cotidiana y mutuos intereses. En este trabajo nos proponemos analizar el papel de dichos vínculos en la formación del poder dentro del Cabildo de Buenos Aires entre 1776 y 1810, periodo en el cual dicho organismo fue afectado por cambios políticos e institucionales que derivaron en el fenómeno conocido por la historiografía como revolución de Mayo.

Uno de los aspectos significativos de nuestra investigación es señalar que los individuos representaban familias y que estas se encontraban vinculadas entre sí, para controlar el acceso y la permanencia en el concejo. En una sociedad de antiguo régimen como la porteña tardocolonial (Guerra, 1993, pp. 89-90) que enmarca: "el reconocimiento social de todo hombre y mujer perteneciente a la elite capitular derivaba directamente de sus familias" (Valle, 2014, p. 59) puesto que dicha sociedad sustentaba su funcionamiento en cuerpos que en individuos y también, desde una perspectiva práctica, porque la duración de las familias en el tiempo supera la existencia de una sola persona, en función de las estrategias de reproducción que se pusieran en marcha. No obstante, hay que aclarar que las relaciones entre algunos integrantes de la elite concejil distaban de ser apacibles porque en su seno surgían enfrentamientos que, en la mayoría de los casos, tenían algún sustrato económico (Valle, 2006, p. 66).

Denominamos elite capitular a este grupo de actores y la consideramos un recorte de la elite porteña que se caracterizaba por el ejercicio de oficios concejiles. Las familias que la integraban fueron generando a lo largo del tiempo vínculos entre sí a través de diferentes comportamientos. En este sentido, la familia, además de un grupo relacional, es una entidad colectiva y una estructura de poder, que establecía relaciones interpersonales entre sus miembros y con el resto de la sociedad. Esos vínculos no estaban desprovistos de conflictos y poseían sus propios intereses y objetivos que, en muchos casos, generaban controversias dentro de las familias o de la propia red. A modo de ejemplo de conflicto por cuestiones económicas entre individuos de una misma familia podemos citar a los hermanos Martín y Blas de Álzaga. Ambos compartían actividades comerciales vinculadas con la distribución de mercaderías entre Buenos Aires y Potosí, que eran los lugares de residencia de cada uno, respectivamente. El interés de Blas por separar esos negocios, luego de casarse sin el conocimiento ni la anuencia de su hermano, provocó una serie de acciones judiciales que los enfrentaron en mutuas acusaciones. Este caso expone las consecuencias de un matrimonio que no responde a la estrategia familiar de expansión de negocios porque tanto su esposa como su suegro terminaron generando un proceso judicial contra su hermano Martín. Podemos ilustrar las controversias entre individuos de diferentes familias con un enfrentamiento 
entre Manuel Warnes y Antonio Escalada que comenzó en 1786 por un deslinde de terrenos y que, a partir de 1791 pasó de la esfera privada a la pública cuando el virrey Nicolás de Arredondo dispuso que Warnes no podía ser elegido capitular porque Escalada le había iniciado una causa criminal. El conflicto se trasladó al seno del cabildo, que resistió la orden virreinal. Finalmente, por real cédula del 24 de diciembre de 1795 se desaprobó lo actuado por el funcionario y se instruyó a la audiencia a reconciliar los ánimos de ambos litigantes por lo escandalosa de la causa (Valle, 2006, pp. 68-74). No obstante, y a pesar de la existencia de casos similares a los presentados, al margen de los enfrentamientos puntuales entre algunos individuos o entre familias, fue sumamente relevante la existencia de un marcado interés por conservar e incrementar los negocios y los patrimonios dentro de la elite capitular.

Estas reflexiones permiten comprender que un análisis interno del cabildo puede conducirnos a explicar que el control de su vida política, es decir, las decisiones de gobierno y el rumbo del organismo y de la ciudad, estaban en manos de vecinos de sectores altos de la sociedad, portadores de prestigio social y comerciantes en su mayoría, que ejercieron el gobierno urbano. El acceso de los miembros de la elite capitular se producía a partir de un proceso eleccionario que se realizaba el día 1 de enero de cada año en la sede del ayuntamiento, según lo que establecían las ordenanzas del cabildo. El alcalde de primer voto era quien hacía las nominaciones para cada cargo, que según la legislación debía ser desempeñado por vecinos. Esas propuestas eran apoyadas o, como sucedió en algunos casos, desestimadas por los capitulares salientes sugiriendo otros candidatos. Las elecciones debían ser confirmadas por el virrey o por el gobernador intendente, este último a partir de la vigencia de la Real Ordenanza de Intendentes. Fue así que un sector de la elite porteña, con el suficiente respaldo económico y prestigio social, se constituyó en beneficiario de esas leyes y controló la institución incorporando, a esas dos características, el poder político. Estas consideraciones no sólo no constituyen un aspecto menor, sino que determinan la necesidad de tener en cuenta la composición del ayuntamiento al momento de analizar el poder municipal y las acciones políticas de estos organismos

En las fuentes encontramos algunos indicios sobre la existencia de reuniones secretas previas a las nominaciones en las que se resolvieron las propuestas que haría el alcalde de primer voto. En dichas reuniones suponemos la presencia de representantes de las familias favorecidas de la elite capitular en el proceso eleccionario en el que los capitulares salientes elegían a los entrantes. Esas nominaciones guardan estrecha relación con el ejercicio del poder no sólo en las del gobierno urbano (que involucra el establecimiento del temario de las reuniones como las resoluciones respecto de los asuntos tratados), sino también en los beneficios simbólicos, económicos y de ampliación de su poder e influencia que obtenían las familias que estaban detrás de quienes desempeñaban los cargos. Entre los primeros, de prestigio, podemos señalar que la designación de funciones anexas a las regidurías, muestran la estrecha relación entre los cargos y el prestigio de las personas nominadas para desempeñarlos, asociado al de la familia que cada uno de ellos integraba. Uno de los destacados por su capital simbólico era el de alférez real, cuya responsabilidad consistía en sacar el real estandarte, alzarlo y tremolarlo, en las ceremonias y en las campañas militares, con la debida solemnidad y fidelidad. Debía ocupar el mejor lugar delante de los capitulares para tener el primer voto, obteniendo un lugar destacado después de los alcaldes, en la casa del ayuntamiento, en los actos de recibimiento y en las procesiones.

Los beneficios económicos del ejercicio del poder capitular provenían de las funciones delegadas. Es el caso, por ejemplo, de Gregorio Ramos Mejía, que recibió una gratificación de 200 pesos, procedentes de los fondos de propios por buscar antecedentes en el archivo, sobre una con- 
sulta a la que el cuerpo debía responder ${ }^{1}$ También se originaban en las funciones anexas al cargo de regidor, por las que se percibía un ingreso como son los casos del alguacil mayor, que obtenía regalías por comisiones de mensuras, y del fiel ejecutor, que desde 1758 , aludía un bolsillo de dinero, derivado de los aranceles cobrados que repartía entre él y sus ayudantes. El déficit en las cuentas del ayuntamiento dio lugar a la modalidad de los préstamos a interés para solventar los gastos vinculados con la organización de fiestas patronales, el recibimiento de virreyes, la construcción de obras públicas, entre otras. A principios del siglo XIX, entre los prestamistas podemos mencionar a Anselmo Sáenz Valiente, José Riera, Francisco de las Llagas Lezica. ${ }^{2}$ También era posible lograr otras prerrogativas como, por ejemplo, alquilar una casa del Cabildo a bajo precio como fue el caso del alguacil mayor Manuel Mansilla entre 1779 y 1810 hasta que obtuvo un terreno en donación y una pensión del concejo.

Así, pertenecer a la elite capitular y haber desempeñado cargos concejiles ofrecía posibilidades de expansión del poder e influencia de las familias en otros como la procuración en Corte, que permitía la cercanía a la corona y a los contactos. Un ejemplo es José Requena, yerno y socio de Martín de Álzaga, designado el 10 de enero de 1810, y de Francisco de Paula Ugarte $3^{3}$ hijo de Francisco de Ugarte, varias veces regidor e integrante de la influente familia BasavilbasoAzcuénaga, al igual que Álzaga.

El antecedente de desempeño en cargos concejiles permitió avalar solicitudes para los de otras instituciones como la Audiencia 4 instancia judicial superior a las alcaldías ordinarias, y el Consulado, espacio de poder vinculado con cuestiones económicas, de tipo comerciales, hacia las cuales migró la elite concejil. Las fuentes muestran que haber sido capitular constituía un antecedente valioso para acceder a otro empleo fuera de la institución. Las listas de los integrantes del Consulado exhiben apellidos de las familias concejiles, evidenciando su componente económico. En su primera acta, 2 de junio de 1794, se encuentran desempeñando cargos José Blas de Gainza, Juan Esteban de Anchorena, Juan Antonio de Lezica, Francisco Ignacio de Ugarte, Saturnino Sarasa, Isidro José Balbastro, Manuel del Cerro Sáenz, Pedro Díaz de Vivar, Joaquín de Arana, Diego de Agüero, Cristóbal de Aguirre y Manuel Belgrano (Río de la Plata, 1936, p. 197). “Todos estos comerciantes habían sido capitulares, formaban parte de la red de solidaridad y de la elite concejil. Incluso la casa alquilada para el funcionamiento de la institución pertenecía a los herederos de Vicente de Azcuénaga, estando las tramitaciones a cargo de su yerno, Santa Coloma. El Cabildo, prestaba sus instalaciones para las primeras reuniones del consulado" (Valle, 2014, p. 196). Estas cuestiones no sólo no constituyen un aspecto menor, sino que determinan la necesidad de tener en cuenta la composición del ayuntamiento al momento de analizar el poder municipal y las acciones políticas de estos organismos.

Por último, la elite capitular es una categoría que se sustenta en una red de relaciones, dinámica, imbricada y compleja, con solidaridades y antagonismos, que hace posible reconocer la existencia de vínculos recíprocos, más o menos fuertes (Ramella, 1995, pp. 20-21) e indisolubles entre sus

\footnotetext{
${ }^{1}$ Cabildo, 17 de setiembre de 1790, p. 416. Acuerdos del Extinguido Cabildo de Buenos Aires (1925-1933) (en adelante, AECBA), serie III, t. Ix, libro LXV. Archivo General de la Nación (AGN).

${ }^{2}$ Cabildo, 25 de octubre de 1803, p. 294; 1 de febrero de 1804, p. 376; 20 de abril de 1804, p. 403, y 13 de enero de 1810 , p. 18, serie IV, t. IV, libro LXV. AECBA-AGN.

${ }^{3}$ Cabildo, 10 de enero de 1816, pp. 16-17, serie Iv, t. IV, libro LXV. AECBA-AGN.

${ }^{4}$ Títulos de Bernardo Gregorio de Las Heras (1792). Solicitud de Antonio de Escalada para el cargo de alguacil mayor (1797); Pedido de Manuel Belgrano Peri para ser alguacil mayor (1782). Venta de cargos. Buenos Aires, legajo 151. Archivo General de Indias.
} 
integrantes. Cada relación o lazo permitió a los individuos y a las familias tener un trato directo o indirecto con todos los individuos o familias con quienes su alter estaba vinculado (Rodríguez, 1995, pp. 14-15). El acceso a los recursos (simbólicos y materiales) que circularon en el interior de la elite capitular como el prestigio social, el respaldo económico o el poder político pudo hacerse en forma directa o indirecta, en este último caso a través de familias que actuaron como nexo con otras y que obtuvieron esa función recurriendo a las estrategias más utilizadas, es decir, al matrimonio y al compadrazgo. Esa red funcionó como cimiento, como una estructura de lazos sobre la que se asentó el edificio de la citada elite. Coincidimos con Zacarías Moutoukias cuando sostiene que los vínculos constituyen un instrumento que permite observar la dinámica del sistema y del espacio en el que se situaron los mecanismos que los generaron (Moutoukias, 1995, p. 229), reflexiones que pueden aplicarse a la red de familias capitulares.

La red total -o extensa- dentro de la definición esgrimida por Moutoukias (1995, p. 231) está constituida por el conjunto de la elite porteña, mientras que la élite concejil configura una red parcial desprendida de la primera. El rasgo común de los individuos que integraban esta red parcial fue el de haber sido elegidos para desempeñar cargos concejiles. En coincidencia con las expresiones de Michel Bertrand respecto a que el verdadero desafío radica en utilizar el concepto de red de manera que constituya, metodológica y analíticamente, "una herramienta capaz de dar contenido y significado a observaciones que sin él quedarían en un nivel anecdótico" (Bertrand, 2000, p. 78), vemos ahí una perspectiva para analizar la elite capitular porteña tardocolonial. Nuestro interés es el de aportar nuevas posibilidades de análisis que puedan incorporarse a las utilizadas por los historiadores. Si bien es una herramienta de alto valor metodológico, también puede ser utilizada con otras perspectivas, o evitada según el tema que se aborde, los datos que se posean, los objetivos del historiador y su formación, entre otras circunstancias. No obstante, posee también limitaciones porque si bien recupera los individuos y los grupos y proyecta un entramado social, se trata de un recorte espacio-temporal específico en el que, según el aspecto que se estudie, se pierden dimensiones de análisis.

Desde esta perspectiva, el proceso de construcción de la red de relaciones o de solidaridad tuvo su origen en la familia ya que esta actuó como un factor de cohesión interna, constituyéndose, a su vez, en un ámbito tendente a la reproducción económica y social. De esta manera, se esperaba garantizar tanto su perduración en el tiempo, como su ejercicio del poder económico, social y, fundamentalmente, político. Las estrategias de reproducción desarrolladas por aquéllas fueron diversas en función de sus posibilidades de actuación y también de las oportunidades de sus elecciones. Nos centraremos en este artículo en dos estrategias fundantes de la red por cuanto fueron las más frecuentes y duraderas: el matrimonio y el parentesco religioso (padrinos de bautismo o testigos de casamiento).

A la red capitular que trabajamos como "un específico conjunto de conexiones entre un definido grupo de personas, con la propiedad adicional de que las características de dichas conexiones, como un todo, pueden usarse para interpretar el comportamiento social de las personas involucradas" (Mitchell, 1969). La idea de red se asocia con el hecho de que cada familia o clan mantiene lazos con otras familias o grupos familiares, a través de los individuos que las componen y que cada uno de ellos se encuentra, a su vez, relacionado con otros (Senor, 2005). Esto permite analizar e interpretar su comportamiento y consecuentemente los de sus integrantes, en tanto actores sociales, en el contexto de las relaciones existentes y también el funcionamiento de los integrantes de la red (Mitchell, 1969, p. 2; Rodríguez, 1995, p. 10). 
En suma, la red de familias capitulares fue producto de las relaciones entre actores sociales de tipo antiguo, corporativos, cuyos lazos dependieron de estrategias familiares para a asegurar su permanencia en el cabildo porteño. Pensada como una estructura parcial, parece haber sobrevivido a lo largo del periodo que analizamos, por lo cual, podemos decir que estamos ante una estructura de larga duración que comenzó a configurarse desde principios del siglo XviII, aunque la abordaremos desde la creación del virreinato del Río de la Plata, en 1776, hasta el 25 de mayo de 1810 en que se erigió la junta de gobierno. Hemos tomado este periodo porque en esa época el cabildo de Buenos Aires dejó en evidencia mucho de su poder político fruto del prestigio social y del poder económico de quienes conformaban la elite capitular.

Hemos acudido a la metodología de redes 5 porque ese poder radicaba en la red de familias. Si bien sus vínculos y la distribución de bienes materiales y simbólicos lo hacían circular y retroalimentarse, hay que reconocer que la desigualdad de dicho reparto hizo que algunas concentraran más poder que otras, en el sentido de nominaciones a cargos capitulares.

Los análisis de redes sociales históricas y de poder tiene un trabajo fundacional en las contribuciones de John Padgett (1994) y Padgett y McLean (2006) para las familias florentinas de la época del renacimiento. En países de legado anglosajón, pueden mencionarse contribuciones sobre acción colectiva, como la rebelión de Whiskey (Gould, 1996) o la que destaca la centralidad de intermediación de Paul Revere y Joseph Warren en la redada nocturna que dio origen a la revolución americana (Han, 2009). Asimismo se ha estudiado, aunque no utilizando herramientas de análisis de redes sociales, la influencia de la pertenencia a grupos políticos en la rama revolucionaria de Vermont tambien durante la revolución americana (Hillmann, 2003). En el otro extremo del mundo, encontramos un estudio de las redes de mercaderes y su interacción del Sydney colonial como una estructura que mitigaba la incertidumbre económica de un proyecto colonial en ciernes (Johns y Ville, 2012).

Existen trabajos de análisis de redes sociales aplicados a estudios coloniales en Latinoamérica que pueden ejemplarizarse con estudios urbanos (Granados, 2006) y hacendados (Sánchez, 2007) de México y Guadalajara (Ibarra, 2007) y Puebla (Morales, 2006). Contribuciones específicas estudiaron las elites y sus redes sociales en el periodo colonial en el caso de Maracaibo (Berbesí, 2007) y la elite colonial de Guatemala (Casarola, 2003). Precisamente este último trabajo revela la relación de las redes sociales con el poder colonial analizando en profundidad la historia y estrategia matrimonal de la elite guatemalteca, utilizando principalmente un estudio de bloques cohesivos y su relación con el poder económico y político. Rodríguez (2015), por su parte, utiliza herramientas de redes sociales para estudiar las relaciones que definieron el accionar de un corsario francés en el Caribe de finales del siglo xviII. Sandrín (2013) presenta, a su vez, la red de proveedores de los asentistas de víveres en Montevideo, es decir aquellos que proveían de insumos a los barcos que recalaban en el puerto. Por su parte, Borucki (2011) describe una época contemporánea al análisis del presente artículo, de hecho trabaja con muchos de los individuos que se mencionarán aquí también. Si bien se enfoca en el tráfico de esclavos y su importancia ecónomica como parte de una red de comercio, el análisis no abarca el caso de la conformación del poder político colonial aunque brinda información de respaldo sobre la relevancia de diversos actores. Como puede observarse, el estudio de las redes sociales en el periodo colonial americano puede describirse como

\footnotetext{
${ }^{5}$ La teoría de redes sociales se desarrolló desde la década de 1930, aunque el término fue acuñado con el trabajo de Barnes (1954) sobre una pequeña comunidad de pescadores.Véase también, Scott (2000) y las críticas de Gribaudi (1998) a su esquema.
} 
enfocado al estudio del poder familiar como parte del sistema político-económico de una región administrativa determinada. En términos de la metodología empleada el uso de herramientas de análisis de redes sociales no es algo tan común dentro de este contexto.

En el caso rioplatense podemos encontrar estudios de familias de empresarios coloniales que analizan circuitos mercantiles y redes matrimoniales y comerciales para Jujuy (Conti y Gutiérrez, 2009; Ferreiro, 2010). Respecto al poder político dentro del cabildo como institución, podemos mencionar un estudio de redes sobre decisiones de elección en el cabildo de Córdoba (Aramendi, 2011). El análisis de redes es básicamente narrativo con el uso de un grafo (Aramendi, 2011, p. 9) y no utiliza métricas específicas (tanto grupales como individuales) para profundizar su relato.

En líneas generales, la bibliografía sobre instituciones coloniales no ha hecho un uso frecuente de las herramientas metodológicas de las redes sociales y, en su lugar, se propusieron análisis de tipo narrativo-económico fundados en perspectivas genealógicas. En función de eso, el objetivo de este artículo consiste en mostrar la relación entre las nominaciones para desempeñar cargos capitulares que se realizaron a principios de cada año y la posición relativa de los individuos y las familias concejiles en la red, aplicando la metodología de análisis de redes sociales.

La teoría de las redes sociales se asienta en la premisa de que las relaciones sociales pueden modelarse como un grafo de puntos denominados nodos unidos por líneas conectoras denominadas enlaces. En ese sentido, es imposible disociar la forma del grafo de su contenido porque la red es la expresión abstracta de las relaciones establecidas entre los actores y aquel, es decir, lo que se genera o intercambia a partir y a través de los vínculos. En otras palabras, las conexiones entre actores individuales implican intercambios de recursos (información, bienes y servicios, capital cultural, apoyo emocional, entre otros), lo que conforma un sistema interpretable. Sin embargo, este intercambio no es, en modo alguno, obligatorio, sino que constituye un potencial de uso, una posibilidad de que los nexos existentes entre los actores se utilicen o no, así como la intensidad de uso en el primer caso, lo que determina que las configuraciones de relaciones entre actores sean cambiantes (Lin, 2001). El uso que los actores hagan de los recursos con que cuentan depende de los fines para los que los quieran emplear, por lo que uno de los supuestos de la teoría es que los actores de un sistema están dotados de una racionalidad instrumental. En este contexto, el éxito o fracaso de un actor dentro del sistema en relación con su racionalidad instrumental, está totalmente ligado a la calidad de la utilización que este haga de sus recursos en el contexto de la red siguiendo planes contingentes, denominados estrategias.

Los actores sociales, la elite capitular, son los sujetos que establecen y sostienen los vínculos, mientras que la unidad de análisis la constituyen los lazos que mantienen los actores porque estos son los que determinan las estructuras en cuyas posiciones se sitúan. Podemos señalar que los lazos familiares y religiosos son determinantes en el acceso a los cargos políticos con más alta jerarquía en una sociedad densamente conectada como la bonaerense tardocolonial. La explicación de los comportamientos de los actores sociales conlleva investigar esos lazos relacionales que posibilitan las transferencias de recursos (materiales y simbólicos) en el interior de la red, porque todo actor participa en un sistema social que implica a otros actores que son puntos de referencia significante en las decisiones mutuas, ya sea porque operen desde la cooperación o desde el conflicto, puesto que también existen asociaciones que por rivalidad o competencia son antagónicas.

En este marco, resulta de interés rescatar algunos reparos metodológicos planteados por Ponce Leiva y Amadori (2008) sobre las dificultades de realizar un estudio de redes sociales en la América previa a los procesos independentistas, entre los cuales señalaremos dos: $a$ ) el problema de la insu- 
ficiente diferenciación de conceptos (familia, grupo, red) y $b$ ) los problemas de aplicación práctica, referidos a la selección de actores, la consideración de la red parcial o total y, la caracterización de los vínculos (Ponce Leiva y Amadori, 2008, 23).

En las secciones que siguen intentaremos dar respuesta a estos senderos metodológicos para presentar el escenario de la red familiar y de compadrazgo de la elite capitular porteña. En primer lugar, analizaremos la red de individuos pertenecientes a la red capitular y, en segundo, haremos lo propio con la red de familias. De esta manera, esperamos demostrar si la perspectiva historiográfica que ubica a los actores del periodo tardocolonial como actores colectivos de antiguo régimen, según la cual el poder radicaba en las familias y no en sus individuos, puede corroborarse con el análisis de redes sociales.

\section{INDIVIDUOS, FAMILIA Y RED EN LA ELITE CAPITULAR}

Los datos fueron obtenidos de registros eclesiásticos de la catedral de Buenos Aires, documentación édita y fuentes inéditas extraídas del Archivo General de la Nación de Argentina ${ }^{6}$ La selección de actores para realizar el análisis de redes sociales del cabildo bonaerense en el periodo 1776-1810 comprendió inicialmente una red de 1215 personas, hombres y mujeres, de los cuales fueron procesados en una primera muestra 548 individuos, vinculados entre sí, que componen una red agrupada en 114 familias, denominada precisamente, red familiar. Debe tenerse presente que la población aproximada de la ciudad de Buenos Aires para esa época promediaba los 32000 habitantes (Besio, 1939, p. 157; Johnson y Seibert, 1979, pp. 107-119; Johnson, Socolow y Seibert, 1980, pp. 329-349), por lo que la muestra inicial abarca $3.8 \%$ de la población, mientras que la red analizable comprende $1.5 \%$ de la población total de la ciudad.

Los actores fueron seleccionados por haber determinado la existencia de, al menos, una de las siguientes relaciones entre ellos $a$ ) el matrimonio en primera, segunda y terceras nupcias; $b$ ) relación consanguínea, hijos y hermanos; $c$ ) testigo, padrino, madrina de casamiento; $d$ ) testigo padrino, madrina de bautismo; $e$ ) testigo de defunción, y $f$ ) socio comercial.

Cada actor que registraba alguna de dichas relaciones fue añadido a la red con un enlace. La red familiar, por su parte, se construyó a partir de asociar a los miembros individuales a las diferentes familias capitulares. Metodológicamente, las redes de matrimonio mantienen el patrón (Newman, 2005; White, 2005) de ser ralas (con baja densidad) por la propia naturaleza de los enlaces. Asimismo, estos últimos entran en la categoría de enlaces fuertes, es decir relaciones con interacción cotidiana y fuente directa de apoyo emocional u otros recursos (véase figura 1).

Los mayores valores la figura 1 representan a actores que fueron cabezas de sus familias como Juan Lezica y Torrezuri (243), Marcos José de Riglos (321), Vicente de Azcuénaga (545) y Manuel Antonio Warnes (295), por citar algunos ejemplos. También muestra miembros de familias con enlaces que conectan con otros integrantes de la red, como es el caso de Francisco Ignacio de Ugarte (127), yerno de Azcuénaga. Además, se encuentran mujeres que eran esposas o hijas de cabezas de familia como María Ignacia Javiera de Riglos (379), hija de Marcos José de Riglos;

\footnotetext{
${ }^{6}$ Se han consultado fuentes éditas, como los libros de Jáuregui (1989), Fernández Burzaco y Barrios (1991), Udaondo (1945), Cutolo (1978, tt. 1-5) y Molina (2000). La información fue complementada con los aportes de los Acuerdos del Extinguido Cabildo de Buenos Aires, con las referencias familiares extraídas de su archivo (AGN, X-19-3-1 a 19-5-8) y de su correspondencia (AGN, 1728-1806, IX-19-7-5; IX-20-9-6; IX-20-9-7; IX-20-10-1; IX-20-10-2; IX-20-103, legs. 1-5). Para más referencias véase Valle (2014, pp. 311-315).
} 


\section{FIGURA 1. MIEMBROS CODIFICADOS DE LA RED DE FAMILIAS CAPITULARES} DE BUENOS AIRES (1776-1810) CON LOS MAYORES VALORES DE GENTRALIDAD DE INTERMEDIACIÓN

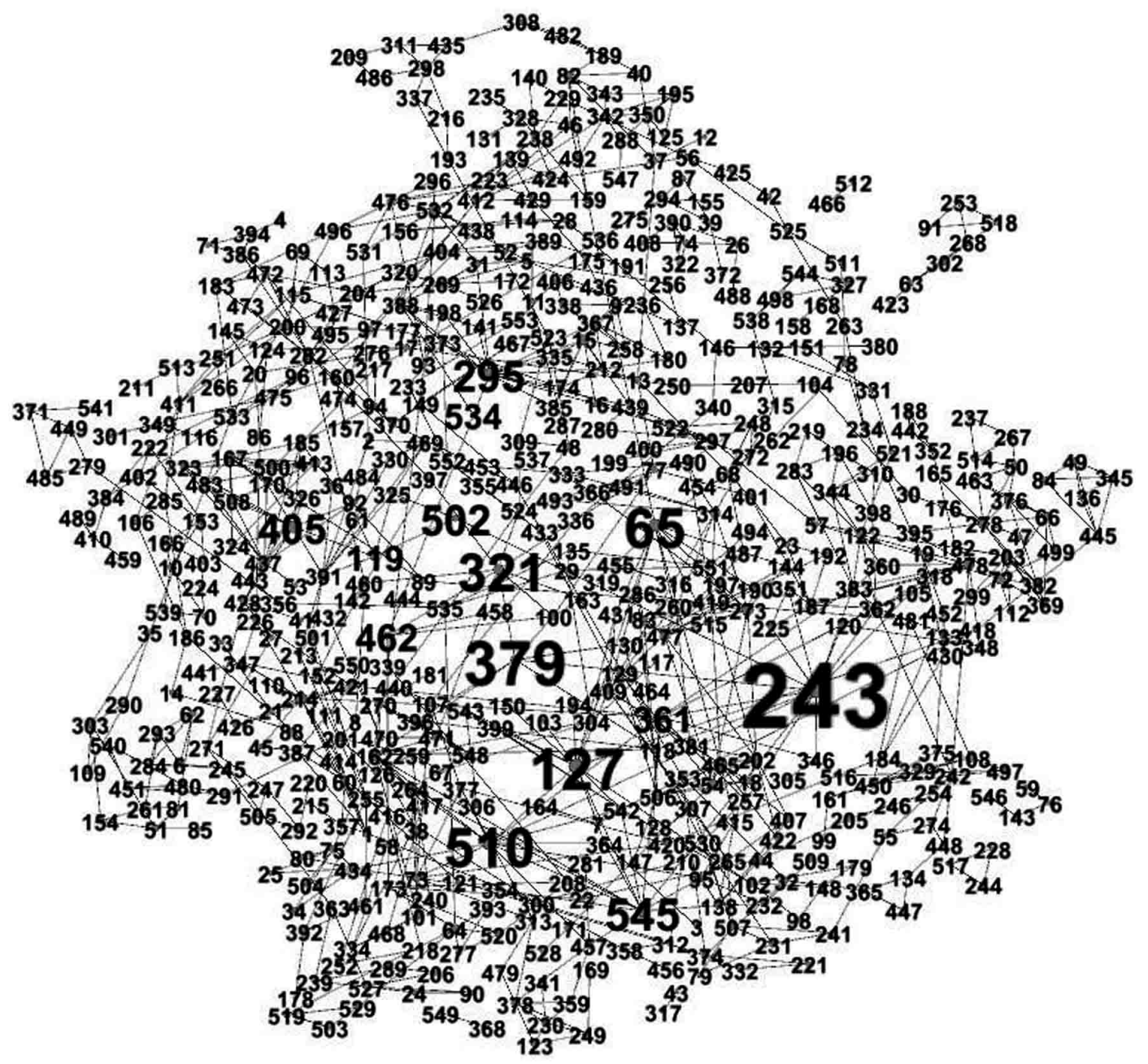

Nota: los nodos codificados como números representan a los miembros de la red y el tamaño de los números representa, en escala, el valor de centralidad de intermediación de los integrantes.

Fuente: elaboración propia.

Rosa de Basabilbaso, esposa de Vicente de Azcuénaga e hija de Domingo Basavilbaso, quien fuera cabeza de familia hasta que ocupó su lugar Azcuénaga; Tomasa Warnes, hija de Manuel Warnes y María Elena de Alquiza, esposa de Juan Lezica y Torrezuri, entre otras.

Estos datos identifican las conexiones de cada integrante en el interior de la red, y establecen el papel desempeñado, en ese sentido, no sólo por quienes lideraban cada grupo sino también el papel de las mujeres al vincularse de distintas formas con otras familias. María Ignacia Javiera de Riglos se casó en 1787 con Francisco de la Mata y Bustamante, elegido regidor dos años des- 
pués. Tres yernos de Rosa de Basabilbaso y Vicente de Azcuénaga fueron capitulares luego de sus matrimonios y también lo fue uno de sus hijos varones (Miguel de Azcuénaga). Ambas mujeres se encuentran entre los cinco índices mayores de centralidad de intermediación, lo cual permite pensar en el grado de relaciones que poseen en el interior de la red y el impacto de estas últimas en el ejercicio de estrategias como la matrimonial o la religiosa, para el acceso y la permanencia de individuos de la familia o aliados, en el cabildo.

\section{Definiciones y conceptos}

En el análisis individual de la red se determinará bajo diferentes criterios la relevancia de algunos de los miembros destacados. Para ello se recurre al concepto de centralidad, que indica qué miembro o nodo de la red es relevante. Cada tipo de centralidad asigna una métrica (un valor) a un individuo en la red, y del ordenamiento de esos valores se obtiene la posición jerárquica de cada nodo. Esos criterios se basan en distintas formas de interpretar la posición de un agente en la red. Por ejemplo, la centralidad de grado nos indica qué nodo tiene mayor cantidad de enlaces. Cuando la relación modelada es simétrica (como es el caso) entonces la centralidad de grado es la que concretamente mide la importancia del actor. Cuantos más enlaces se establecen con el agente, más destacado es el mismo, por lo que la circulación en la red convierte a este nodo en valioso para la recolección y distribución de información u otro recurso que circule en la red. Los valores mayores de centralidad de grado en grupos densamente conectados conllevan mayor apoyo emocional.

Un segundo criterio es la centralidad de cercanía, la cual registra qué nodo está ubicado a menor distancia (siguiendo la cantidad de enlaces intermedios que unen a nodos distantes en la red) entre todos los agentes. Uno con alta centralidad de cercanía estaría ubicado "a mitad de camino" de todos los agentes y ello lo haría una ruta obligada de traspaso de información en la red.

Una tercera acepción de centralidad es la de intermediación, la cual valora muy particularmente a quienes se hallan en posición de puente entre grupos dispersos de la red. Es calculada como la fracción de los caminos más cortos entre otros actores que pasan por ese actor que, en una posición tal es presumible que pueda actuar como intermediario en las relaciones con los otros actores. Esa posición de intermediarios los convierte en importantes porque pueden decidir cómo y a quién traspasar la información. Un ejemplo de esto, es el caso de Juan de Lezica y Torrezuri (código 243, véase figura 1) que posee la misma centralidad de grado que otras cabezas de familias de la red, pero cuya centralidad de intermediación es la mayor de todos.

Finalmente, podemos señalar que la centralidad de autovector es la más formal porque analiza la información de todas las conexiones para favorecer a los agentes mejor conectados en términos de la estructura de conexión global. Es decir, la centralidad de autovector da mayor valor a los actores mejor conectados, pero también a aquellos que están conectados con los mejor conectados (véase figura 2).

En la figura 2 coinciden, por un lado, los nodos que tienen la mayor centralidad de cercanía y de autovector y, por otro, los que poseen mayor centralidad de intermediación y de grado, entre ellos. Esto es un evento particular que no siempre se repite y que depende de la estructura específica de cada red. 


\section{FIGURA 2. EJEMPLOS DE CENTRALIDAD EN UNA SUBRED DE LA RED INDIVIDUAL}
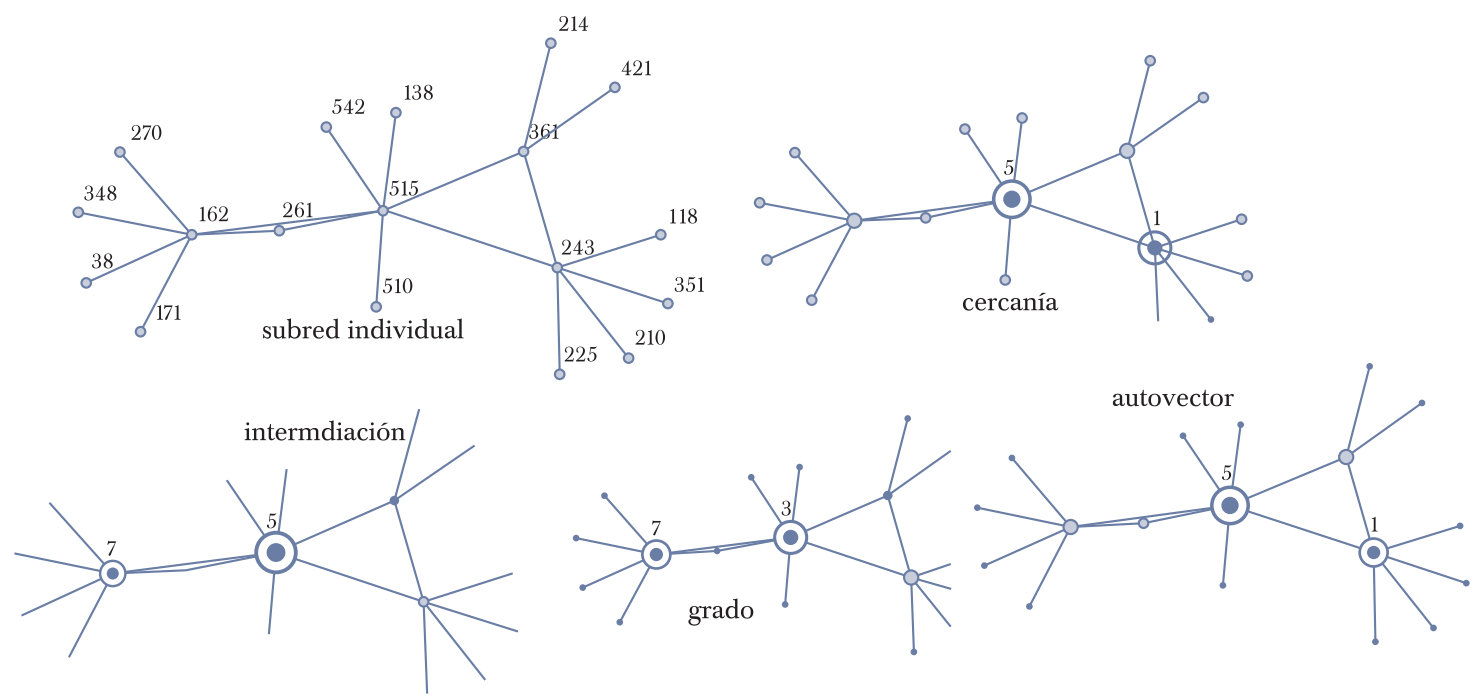

Nota: se muestra una subred individual (un extracto de la red de individuos presentado en figura 1) y cuatro representaciones, a modo ilustrativo, donde se destacan con un círculo externo los dos nodos con mayor métrica respectiva.

Fuente: elaboración propia.

\section{Red de individuos}

La red sociocéntrica comprende 548 integrantes con un total de 889 relaciones (enlaces). Para caracterizarla se realizará primero un análisis de las variables a nivel de red que mostrarán patrones del marco de las interrelaciones. En ese sentido, ciertas características macro brindarán información respecto a las limitaciones de las conexiones particulares.

En el cuadro 1 se consignan los catorce individuos con mayor centralidad de intermediación, ordenados en forma descendente y que fueron seleccionados por su valor estratégico en la red social pues eran las cabezas de las familias capitulares relevantes que, a través del establecimiento de lazos, configuraron la red social que analizamos.

En algunos casos los mayores valores de centralidad de intermediación implican mayor cantidad de relaciones (centralidad de grado) (véanse cuadro 1 y figura 1).

Si tomamos, a modo de ejemplo, el caso de Juan Lezica y Torrezuri (código 241, figura 1), quien muestra el mayor grado de intermediación, debemos señalar su carácter de cabeza de familia de una de las tres que componen el grupo familiar Lezica. Su jerarquía en la red no sólo deriva de las estrategias para ubicar a sus hijos varones en cargos de cabildo, sino también de las que puso en práctica para casar a sus hijas con promisorios candidatos que, luego de las bodas, accedieron además a oficios concejiles. Entre estos últimos también se contaron representantes de familias socialmente prestigiosas, económicamente poderosas y políticamente influyentes en el gobierno urbano de Buenos Aires, como la familia Riglos con la cual se estrecharon vínculos a través de sendos matrimonios en 1773 y 1783. Un ejemplo de ello fue el segundo matrimonio de Juan José de las Llagas Lezica con Juana Petrona de Vera y Pintado, en 1776, luego del fallecimiento de su primera esposa, María Rosa Riglos y San Martín, en 1774. Juana era oriunda de Santa Fe 


\section{CUADRO 1. MIEMBROS Y CARACTERÍSTICAS DE LA RED DE INDIVIDUOS DE LA ELITE CAPITULAR DE BUENOS AIRES (1776-1810)}

\begin{tabular}{|c|c|c|c|c|c|}
\hline Código & Nombre & Género & $\begin{array}{l}\text { Centralidad } \\
\text { de grado }\end{array}$ & $\begin{array}{c}\text { Centralidad } \\
\text { de intermediación }\end{array}$ & Familia \\
\hline 243 & $\begin{array}{l}\text { Juan Lezica } \\
\text { y Torrezuri }\end{array}$ & M & 15 & 44037.5 & $\begin{array}{l}\text { Lezica y } \\
\text { Torrezuri }\end{array}$ \\
\hline 379 & $\begin{array}{l}\text { María Ignacia } \\
\text { Javiera de Riglos }\end{array}$ & $\mathrm{F}$ & 7 & 31465.6 & Riglos \\
\hline 127 & $\begin{array}{l}\text { Francisco Ignacio } \\
\text { de Ugarte }\end{array}$ & M & 15 & 29299.3 & Basavilbaso \\
\hline 65 & $\begin{array}{l}\text { Cristóbal } \\
\text { de Aguirre }\end{array}$ & M & 12 & 28107.7 & $\begin{array}{l}\text { Gómez Cueli/ } \\
\text { Basavilbaso }\end{array}$ \\
\hline 510 & $\begin{array}{l}\text { Rosa de } \\
\text { Basavilbaso }\end{array}$ & $\mathrm{F}$ & 13 & 27765.9 & Basavilbaso \\
\hline 321 & $\begin{array}{c}\text { Marcos José } \\
\text { de Riglos }\end{array}$ & M & 9 & 27026.6 & Riglos \\
\hline 545 & $\begin{array}{l}\text { Vicente } \\
\text { de Azcuénaga }\end{array}$ & M & 12 & 22521.4 & Azcuénaga \\
\hline 295 & $\begin{array}{l}\text { Manuel } \\
\text { Antonio Warnes }\end{array}$ & M & 14 & 21559.5 & Warnes \\
\hline 502 & $\begin{array}{l}\text { Prudencio } \\
\text { de Zavaleta }\end{array}$ & M & 3 & 21086.5 & Desconocida \\
\hline 405 & $\begin{array}{c}\text { María Magdalena } \\
\text { de las Carreras }\end{array}$ & $\mathrm{F}$ & 12 & 20097.8 & Alzaga \\
\hline 462 & $\begin{array}{l}\text { Miguel Fermín } \\
\text { de Riglos }\end{array}$ & M & 5 & 18118.9 & Riglos \\
\hline 361 & $\begin{array}{r}\text { María Elena } \\
\text { de Alquiza }\end{array}$ & $\mathrm{F}$ & 11 & 17065.9 & $\begin{array}{l}\text { Lezica y } \\
\text { Torrezuri }\end{array}$ \\
\hline 119 & $\begin{array}{l}\text { Francisco } \\
\text { de las Carreras }\end{array}$ & M & 5 & 16509.5 & Alzaga \\
\hline 534 & Tomasa Warnes & $\mathrm{F}$ & 3 & 16317.6 & Warnes \\
\hline
\end{tabular}

Fuentes: elaboración propia con base en datos recolectados por los autores.

y su hermana, Rafaela de Vera y Pintado, se convirtió en 1783 en la esposa del gobernador de Montevideo Joaquín del Pino, quien en 1801 fue designado virrey del Río de la Plata (véanse Fernández de Burzaco, 1991; Valle, 2014).7

Tanto Juan Lezica y Torrezuri como su esposa, María Elena de Alquiza, presente en el décimo segundo lugar en nuestro listado de intermediación, se preocuparon por instaurar estrategias de parentesco religioso que los vincularon con otras familias. Entre ellas, podemos citar a familias como las de Sarasa y Basabilbaso, por ejemplo. Justamente, las mismas estrategias que les permitieron vincularse con otras familias de la red fueron las que les posibilitaron el acceso a los capitales

\footnotetext{
${ }^{7}$ Para designación del virrey Joaquín del Pino, véase Estado 80, N, 76. Archivo General de Indias (en adelante, AGI).
} 
simbólicos y materiales, que circularon en su interior y que fueron las puertas de acceso al prestigio social, el respaldo económico y el poder político. Esas estrategias de reproducción social, económica y política son las que podrían fundamentar los grados de intermediación de cada uno de los miembros del listado que expusimos (Valle, 2014).

\section{LA RED POLÍTICA DE LA ELITE CAPITULAR}

La red política es establecida con base en las familias capitulares que se vinculaban entre sí, cuyos individuos fueron nominados para desempeñar alcaldías de primero y segundo voto o regidurías (de la primera a la sexta) y que, en total, fueron 548. Si bien todos ellos fueron hombres, puesto que las mujeres no tenían acceso al cabildo, todas las métricas de red fueron estimadas incluyendo a estas últimas porque, desde sus lugares en las familias también contribuyeron a posibilitar la construcción de la red política. Prueba de ello son las mujeres que integran el listado de intermediación (véase cuadro 1), entre ellas se encuentran: María Ignacia Javiera de Riglos (segundo lugar), hija de Marcos José de Riglos (alcalde de primer voto) ${ }^{8}$ quien fuera la cabeza de la citada familia y esposa de Francisco de la Mata y Bustamante (alcalde de segundo voto); Rosa de Basavilbaso (quinto lugar), hija de quien fuera cabeza de la citada familia y esposa de Vicente de Azcuénaga; María Magdalena de las Carreras (décimo lugar), esposa de Martín de Alzaga (alcalde de primer voto), cabeza de dicha familia; María Elena de Alquiza (decimosegundo lugar), esposa de Juan Lezica y Torrezuri, cabeza la familia Lezica; y Tomasa Warnes (decimotercer lugar), hija de Manuel Antonio Warnes (alcalde de primer voto), cabeza de la familia. Todas ellas fueron esposas o hijas de jefes de familias políticamente influyentes.

La red estaba conformada por una elite capitular que desarrollaba, desde el cabildo porteño, acciones políticas concretas. Para abordarla analizaremos, en primer lugar, la relación entre la posición de los individuos en la red (producto de las estrategias de reproducción practicadas) y la preponderancia del cargo capitular para el que cada uno fue nominado. Posteriormente, realizaremos un análisis similar para el caso de la red de familias concejiles.

\section{Análisis de la red de familias porteñas}

Esta red familiar reúne 114 familias vinculadas por 171 enlaces. La red así definida admite la presencia de autoenlaces, puesto que miembros de la misma familia pueden establecer relaciones rituales entre sí mismos. El análisis de individuos de la red nos ha ayudado a detectar, a través de diferentes métricas de centralidad, actores puntuales con fuerte ascendencia sobre el resto de los agentes de la red y que, en líneas generales, son quienes dirigen sus familias. El poder dentro de la red parece emerger de la pertenencia a diferentes grupos y parece ser, también, proporcional a la influencia política de los mismos. Para observar si el poder político está asociado a individuos o a sus familias, o a ambos, construimos la categoría red de familias para referirnos a un conjunto de conexiones entre un grupo definido de estas (y de individuos que las integran), que pueden permitirnos interpretar comportamientos sociales, económicos y políticos de quienes las componen. En este marco, el proceso de construcción de la red de relaciones o de solidaridad tuvo su origen en la familia con intención de garantizar tanto su perduración en el tiempo, como su ejercicio del poder económico, social y, fundamentalmente, político. La nominación de los capitulares para el desempeño de los diferentes cargos del cabildo porteño, puede comprenderse, entonces, en un

${ }^{8}$ Entre paréntesis se destacará sólo el cargo más alto. 
FIGURA 3. RED DE FAMILIAS CAPITULARES DE BUENOS AIRES CON ETIQUETAS A ESCALA DE LA CENTRALIDAD DE GRADO (1776-1810)

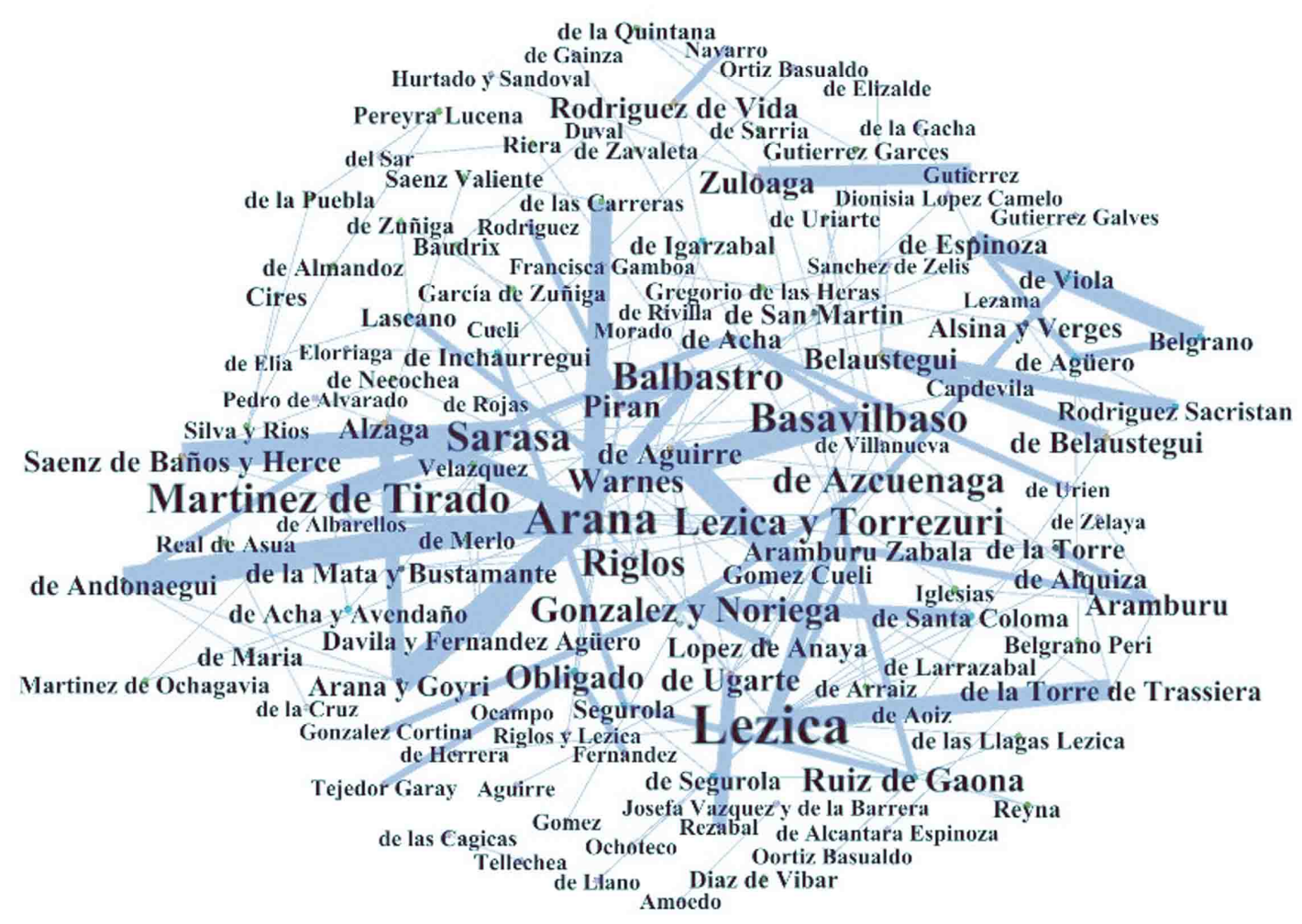

Fuente: Elaboración propia con base en datos recolectados por los autores.

contexto de relaciones que dieron lugar al desarrollo de estrategias de reproducción, orientadas a conservar, consolidar e incrementar el poder de los grupos familiares involucrados. Así se construyó una compleja y poderosa red que funcionó como organización social en el orden público y que, según señala Diana Balmori, surgió en el periodo de transición que va desde la época colonial a la modernidad (Balmori, Voss y Wortman, 1990, p. 22; Valle, 2014, p. 50).

El concepto de familia que utilizamos aquí es el de un grupo de personas que pertenecen por su relación (sanguínea, política, filial) a un mismo núcleo familiar. Existían actores que podían pertenecer a un grupo parental y, a la vez, estar vinculados con otro u otros por lazos de matrimonio o parentesco religioso (padrinos de bautismo o testigos de bodas, por ejemplo). En función de lo expuesto en el 3 , los nodos fueron recreados uniendo a cada miembro de la familia identificado por un apellido en común que etiqueta al nodo, respetando la historia personal conocida de cada miembro e indicando, a través del ancho del enlace, la intensidad de relaciones intra e interfamiliares. Luego fueron recalculadas las métricas de centralidad para realizar un análisis de redes sociales (véase figura 3 ). 
En una red de familias que tiene como uno de sus objetivos la procreación de los enlaces que generan poder y prestigio, como es el caso de la elite capitular que estudiamos, la unidad de análisis puede ser directamente la familia más que cada miembro en particular Por ello, de la red de integrantes de la elite capitular porteña, se pueden distinguir a los individuos no como tales, sino como miembros de un grupo parental. Son estos últimos quienes buscan, a través de sus miembros, conectarse con otras familias a fin de acceder a los recursos de la red.

Debe destacarse que, al crearse estos grupos familiares, muchos miembros individuales quedaron relacionados con otros del mismo grupo, sobre todo porque los lazos generados por los matrimonios tendían a reforzarse con padrinazgos de bautismo o de matrimonios. Con estas estrategias no sólo estrechaban los vínculos interfamiliares, sino que también aseguraban una cierta pertenencia a la familia política en caso de viudez y nuevo casamiento.

Es por ello que los nodos registran autoenlaces. Si bien las métricas de centralidad usadas tradicionalmente por el análisis de redes sociales descartan en el cálculo los autoenlaces, puesto que no tienen una utilidad práctica en la mayor parte de los análisis de individuos de una red (que implicaría el caso de una autorrelación), en nuestro caso es necesario tenerlos presentes ya que son relevantes para entender la función de cada grupo familiar en el contexto de la red social de la elite capitular porteña. Por eso mismo, algunas contribuciones recientes (por ejemplo, Newman, 2005) han aportado indicadores de centralidad que incluyen los autoenlaces en sus cálculos. En función de esas posibilidades, hemos calculado la centralidad de intermediación y cercanía basada en caminos aleatorios (técnicamente denominadas random walk betweeness y random walk closeness, respectivamente). Es por ello que sólo tres indicadores de centralidad son factibles de análisis para esta muestra: la centralidad de grado, la de intermediación y la de cercanía por caminos aleatorios. El cuadro 2 muestra las diez principales familias ordenadas, de mayor a menor, por la centralidad de grado. La familia Lezica y Torrezuri (que comprende tanto a los Lezica como a los Lezica y Torrezuri en sí) representa los valores más altos de centralidad de grado (véase cuadro 2).

\section{Variables y estimaciones de la red de familias capitulares bonaerenses}

En primer lugar, se creó una variable del poder político individual de los miembros llamada IP (índice de poder) en la que a cada persona se le asignó un número del 1 al 9 , según el cargo que ocuparon en el concejo. Corresponde 1 para el síndico procurador y 9 para el alcalde de primer voto, y los cargos intermedios son distribuidos en valores sucesivos según su jerarquía ( 8 , alcalde de segundo voto; 7 , primer regidor; 6 , segundo regidor; 5 , tercer regidor; 4 , cuarto regidor; 3 , quinto regidor; 2 , sexto regidor). La variable que ahora intentamos explicar será PromIP: se trata del valor promedio de la variable de poder político individual para los miembros de cada familia capitular, elaborada por los autores. Ello representa el poder político promedio de cada familia medida por el valor promedio de los cargos a los que fueron nominados sus miembros. A los efectos de este análisis, es una variable explicada o dependiente.

Las variables explicativas serán las de centralidad: grado; intermediación de camino aleatorio y cercanía de camino aleatorio. Otras variables explicativas relevantes son PromIngRed, promedio de año del primer o segundo matrimonio de los miembros de cada familia; PromIngCab, promedio del año de ingreso de los integrantes de las familias al primer oficio en el cabildo, y cargos, es decir, el total de cantidad de veces que se mantuvieron en el mismo cargo los miembros de una familia. 


\section{GUADRO 2. MEDIDAS DE GENTRALIDAD DE GRADO, INTERMEDIACIÓN POR CAMINO ALEATORIO Y GERCANÍA POR CAMINO ALEATORIO PARA LAS DIEZ PRIMERAS FAMILIAS ORDENADAS POR GENTRALIDAD DE GRADO}

\begin{tabular}{lccl}
\hline \multicolumn{1}{c}{ Familia } & Grado & Intermediación & Cercania \\
\hline Lezica y Torrezuri & 37 & 0.006 & 1.21 \\
Arana & 33 & 0.022 & 4.56 \\
Sarasa & 18 & 0.011 & 2.52 \\
Basavilbaso & 15 & 0.013 & 2.84 \\
Gonzalez y Noriega & 15 & 0.014 & 2.94 \\
Balbastro & 14 & 0.008 & 1.65 \\
Martínez de Tirado & 14 & 0.004 & 0.96 \\
Belaustegui & 13 & 0.019 & 4.24 \\
Warnes & 12 & 0.01 & 2.14 \\
Alzaga & 11 & 0.016 & 3.27 \\
\hline
\end{tabular}

Fuente: elaboración propia con base en datos recolectados por los autores.

El cuadro 2 presenta las diez primeras familias ordenadas por la centralidad de grado. Al respecto, puede destacarse la trascendencia de la familia Lezica y Torrezuri, seguida por la familia Arana que, en definitiva, estaba vinculada también con ella por parentesco religioso.

En la figura 3 la etiqueta correspondiente a cada familia se escribe en un tamaño de fuente proporcional a su centralidad de grado y claramente se aprecian las diez principales familias. La familia Lezica y Torrézuri posee la mayor centralidad de grado, lo cual confirma su relevancia en la red y su rol en la recolección y distribución de información y recursos. Por su parte, la familia Arana presenta el índice de intermediación más elevado, que pone en evidencia el impacto de la estrategia del parentesco religioso que le permitió establecer vínculos con el clan integrado por las familias de José de Gurruchaga, Pedro de Alvarado y Martín de Alzaga, y con el formado por las familias de Joaquín de Arana y Goyri, Antonio Obligado, y Francisco Antonio de Belaustegui (Valle, 2014). De esa manera, podemos decir que ocupó una posición de nexo o intermediación conectando grupos dispersos de la red, a lo cual se agrega que Arana también posee el mayor grado de cercanía, lo que convierte a su familia en ruta de tránsito de la información en la red. Estas características fueron importantes en el diseño de la estrategia política que permitió a los integrantes de esas familias ser elegidos para desempeñar cargos de alcaldes de primer y segundo voto, de regidores y sindicaturas en el cabildo, entre 1776 y 1807.

Ahora nos atañe verificar si la relación entre poder político y centralidad observada en la red individual se confirma también a nivel de la red de familias. Una hipótesis planteada por el trabajo es que el poder político emerge e interactúa desde el núcleo de las familias de la elite capitular por tratarse de una construcción de antiguo régimen conformada por actores sociales, ya que: "la acción política en el mundo del Antiguo Régimen tiene un aspecto esencialmente grupal. En primer lugar, porque buena parte de esa política tiene por objeto conseguir para sí mismo o para parientes y allegados puestos directivos en los cuerpos, sobre todo en aquellos que pueden producir mayores beneficios, influencia social o dignidad" (Guerra, 1998, pp. 116-117). 
Para verificar cuáles de las centralidades estimadas demuestra tener algún grado de asociación estadística con la variable PromIP (promedio de IP de los miembros de cada familia) implementamos un modelo de estimación Tobif 9 para establecer la relación estadística entre el índice de poder político (PromIP) de cada familia y las otras variables relevantes. Los datos trabajados con este modelo fueron el promedio del índice de poder de cada grupo familiar (PromIP), que es cotejado con la centralidad de grado, el promedio de cantidad de cargos acumulados por cada grupo familiar (PromCargos) y el año de ingreso en la red (IngRed). Cinco modelos ajustados se aprecian en el cuadro 3 , donde podemos apreciar los coeficientes, sus errores típicos, la significatividad estadística de cada coeficiente obtenida de sus p-valores asociados representadas por asteriscos, y el sigma (significatividad global) de la estimación de cada ecuación.

Los coeficientes para grado y el promedio de cargos desempeñados por las familias (PromCargos) son estadísticamente significativos. Los resultados se interpretan como el impacto de una variable respecto a cambios en la otra, donde el signo positivo o negativo indica la dirección de dicho impacto. Es decir que el año de ingreso de los individuos de cada familia (IngRed) a la red está positivamente asociado con que cada familia tenga un promedio de poder mayor para acceder a las nominaciones a cargos del cabildo. Por otro lado, por cada grado adicional (grado) obtenido por el grupo familiar aumenta en aproximadamente 0.20 el índice de poder promedio (PromIP) de acceder a un grado alto en el cabildo. Una de las formulaciones presenta a Autovector como significativo lo que refuerza el rol positivo del número de relaciones respecto al poder político.

Por lo tanto, el análisis de las familias demuestra que existe una asociación significativa entre el poder político acumulado por ser nominado a cargos concejiles y la cantidad de relaciones establecidas con el resto de la red capitular. En este sentido cuatro familias capitulares (Lezica y Torrezuri, Riglos, Aoiz y Alzaga) que acumulan aproximadamente $30 \%$ del total de grados de la muestra, obtuvieron $50 \%$ de las nominaciones para desempeñar alcaldías, mientras el $50 \%$ restante fue repartido entre las otras familias (Valle, 2014, pp. 171-172).

Una de las familias prolíficas, en cuanto a la cantidad de capitulares que tuvo entre sus integrantes, fue la Lezica, nacida de un tronco común, del que surgieron tres clanes, encabezados por los hermanos Juan José, José e Ignacio de Lezica y Torrezuri, dedicados al comercio. Juan José de Lezica y Torrezuri se casó con Elena Alquiza y Peñaranda, hija de un comerciante español radicado en Buenos Aires desde mediados del siglo xvir. Sus tres hijas mujeres se casaron con Pablo Ruiz de Gaona, Francisco Segurola y Manuel Zapiola, que serían capitulares luego de esos matrimonios. Sus hijos, Francisco de las Llagas y Juan José, ocuparon diferentes cargos concejiles. Éste último se casó con Rosa Anselma de Riglos y San Martín, en 1773, vinculando ambos grupos, y una de sus hijas, de otro matrimonio, hizo lo propio con Francisco Tellechea, también capitular.

Ignacio de Lezica Torrezuri e Ignacia Ozamis dieron lugar a otro brazo de la familia. Una de sus nietas contrajo matrimonio con Juan Antonio Santa Coloma, comerciante y capitular. De esta manera, se vincularon con Gaspar de Santa Coloma, también comerciante destacado, casado, en 1788, con Flora de Azcuénaga, integrante del clan Basavilbaso-Azcuénaga, de comerciantes y capitulares. El personaje destacado de la pequeña rama creada por José de Lezica Torrezuri fue José Pastor, su hijo, que también desempeñó cargos concejiles. (Valle, 2014, pp. 96-99)

\footnotetext{
${ }^{9} \mathrm{El}$ modelo Tobit (McDonald y Moffitt, 1980) fue elegido debido a que la variable dependiente posee gran cantidad de valores agrupados en un valor limitante, en nuestro caso es cero (la mayoría de las familias no registra historial de cargos en el Cabildo).
} 


\section{CUADRO 3. ESTIMACIÓN TOBIT DEL PROMEDIO DE PODER POLÍTICO DE CADA FAMILIA}

\begin{tabular}{|c|c|c|c|c|c|}
\hline PromIP & Modelo-1 & Modelo-2 & Modelo-3 & Modelo-4 & Modelo-5 \\
\hline Intermediación & -0.954 & 0.306 & - & - & - \\
\hline Error estándar & 2.814 & 0.259 & - & - & - \\
\hline Cercanía & 266.3 & - & 93.72 & - & - \\
\hline Error estándar & 640.8 & - & 66.55 & - & - \\
\hline Autovector & -1.45 & - & - & 70.90 & - \\
\hline Error estándar & 36.73 & - & - & $34.53^{b}$ & - \\
\hline Grado & 0.212 & - & - & - & 0.230 \\
\hline Error estándar & $0.091^{b}$ & - & - & - & $0.069^{\mathrm{a}}$ \\
\hline PromCargos & -0.004 & 0.280 & 0.278 & 0.005 & -0.029 \\
\hline Error estándar & 0.164 & 0.186 & 0.179 & 0.205 & 0.151 \\
\hline IngRed & 0.004 & 0.004 & 0.004 & 0.005 & 0.004 \\
\hline Error estándar & $0.001^{\mathrm{a}}$ & $0.001^{\mathrm{a}}$ & $0.001^{\mathrm{a}}$ & $0.002^{\mathrm{a}}$ & $0.001^{\mathrm{a}}$ \\
\hline Constante & -6178 & -6.72 & -6.91 & -6.26 & -5876 \\
\hline Error estándar & $1.82^{\mathrm{a}}$ & $2.13^{\mathrm{a}}$ & $2.19^{\mathrm{a}}$ & $1.88^{\mathrm{a}}$ & $1.675^{\mathrm{a}}$ \\
\hline \multirow[t]{2}{*}{ /Sigma } & 2246 & 3.11 & 3065 & 2850 & 2291 \\
\hline & 0.543 & 0.78 & 0.769 & 0.711 & 0.557 \\
\hline
\end{tabular}

${ }^{\mathrm{a}}$ Significativo al $1 \%$, ${ }^{\mathrm{b}}$ significativo al $5 \%$, ${ }^{\mathrm{c}}$ significativo al 10 por ciento.

Fuente: elaboración propia con base en datos recolectados por los autores.

Se observa que el impacto político de las estrategias matrimoniales y de parentesco religioso ejercidas por los clanes de Lezica fue el acceso a los cargos del ayuntamiento para los cuales fueron nominados sus integrantes entre 1776 y 1810, que también desempeñaron los de mayor prestigio y poder como eran las alcaldías ordinarias de primero y segundo voto. Ejemplo de esto es que de los 16 individuos que integraban dichas familias, entre hijos, yernos y nietos políticos, catorce fueron elegidos para cinco alcaldías ordinarias (tres de primer voto y dos de segundo voto) y 19 regidurías de primero, segundo y tercer lugar. También fueron propuestos para diez regidurías de cuarto, quinto y sexto lugar (con seis defensorías anexas) y para una sindicatura.

El interés del ejemplo que presentamos radica en que ser una familia con poder político en el periodo analizado no se relacionaba tanto con la cantidad de cargos desempeñados en el cabildo, sino con la calidad de los oficios para los que se elegía a los integrantes de la misma y con la posibilidad de permanecer en la institución a lo largo del tiempo. En ese sentido, podemos señalar que "los cargos de mayor calidad eran los del núcleo de poder del consejo, y en ellos se desempeñaron, mayoritariamente, los miembros de las familias más reconocidas y los clanes más prestigiosos, quienes fueron los verdaderos responsables de las decisiones y las acciones de la institución” (Valle, 2014, p. 179). Estos fueron los casos de grupos familiares como los Lezica, Riglos, Aoiz y Alzaga, que ocuparon $50 \%$ de los cargos concejiles en el periodo. 


\section{Conclusiones}

Este trabajo ha explorado la relación existente entre las nominaciones realizadas para desempeñar cargos en el Cabildo de Buenos Aires cada 1 de enero, entre 1776 y 1810, y la posición relativa de las familias en la red, aplicando la metodología de análisis de redes sociales para analizar la red familiar de los grupos concejiles. De esta manera fue posible convertir la información de las redes en un formato numérico, que nos permitiera establecer asociaciones estadísticas y contrastar los resultados obtenidos en cada una de las redes a fin de determinar si un indicador de poder político se asociaba con las familias. Diseñamos para ello una variable de poder promedio (PromIP) que establecía una escala de valores vinculada con la relevancia del cargo al cual había sido nominado un actor que pertenecía a cada familia concejil implicada.

Los hallazgos estadísticos demuestran que los indicadores de centralidad que afirman la importancia de miembros de una familia que ocupan posiciones estratégicas como puente (intermediación) entre subgrupos de otro modo desconectados o localizados a mitad de camino (cercanía) no presentarían relevancia para explicar algunos componentes del poder político de familias como la de Arana, por citar un ejemplo. La centralidad de grado de las familias, por su parte, sí aportaría elementos a la construcción del poder político dado que la mayor cantidad de vínculos vuelve influyente a un grupo familiar y se encuentra asociado con el indicador de poder que diseñamos. Hemos presentado el caso de Lezica y Torrézuri para ilustrar esto.

En este contexto, hay que señalar que las conexiones individuales derivan, mayormente, de pertenecer a una familia con numerosos lazos. Frente a la pregunta acerca de cómo se produce la construcción de esos vínculos, los resultados de nuestra investigación dejan en evidencia que la familia concejil es, justamente, la que permite a través de estrategias matrimoniales el ingreso a la red de los individuos que no son descendientes de capitulares y luego se produce, en la mayoría de los casos, la nominación a cargos del cabildo. Es de suponer que una vez dentro de la red, desde la familia que lo recibió en su seno, el individuo mantendrá las relaciones con otras y generará nuevos lazos tendientes a la reproducción económica, social y política. Podemos señalar, a manera de ejemplo que hubo matrimonios entre grupos poderosos, en términos de influencias y de poder político como fue el caso de bodas entre los Lezica y los Riglos, que constituyeron uniones entre dos de los clanes más antiguos, prestigiosos socialmente, poderosos económicamente y de fuerte tradición concejil en el cabildo porteño. Si bien este tipo de relaciones complejiza los vínculos porque genera lazos entre grupos que ya poseen sus propias conexiones, permite vislumbrar la complejidad de la red de familias como estructura que contiene múltiples relaciones dinámicas y cruzadas. La red también nos hace observar el carácter evasivo del poder como una de las causas que hicieron necesario utilizar estrategias de reproducción, como los matrimonios y el parentesco religioso, para vincular familias y configurar un entramado extenso que permitiera mantenerlo en su seno. La nominación y el acceso de los integrantes de la elite capitular a los cargos concejiles, confirió un sentido político a las familias capitulares y las transformó en clanes influyentes, portadores de poder e involucrados con el gobierno urbano y sus acciones (Valle, 2014, pp. 97-99).

Las estrategias de reproducción, y sobre todo la matrimonial, estuvieron de este modo exitosamente asociadas con las nominaciones para acceder a los altos cargos del concejo. Esto se reafirma luego estadísticamente al quedar en evidencia que en el caso de las familias que presentamos, el poder político se vinculaba también con poseer mayor cantidad de conexiones, tanto con otras familias como también dentro de la propia. 


\section{LISTA DE REFERENCIAS}

Aramendi, B. M. (2011). ¿Poder local versus poder real? Conflictos entre el Cabildo de Córdoba y el Gobernador don Joaquín Espinosa y Dávalos. Andes, 22(1), 73-97.

Balmori, D., Voss, S. F. y Wortman, M. L. (1990). Las alianzas de familias y la formación del país en América Latina. México: Fondo de Cultura Económica.

Barnes, J. A. (1954). Class and Committees in a Norwegian Island Parish. Human Relations, 7(1), 39-58. DOI: $10.1177 / 001872675400700102$

Berbesí, L. (2007). Redes sociales y poder político: Maracaibo, 1787-1812. Revista de Artes y Humanidades, 8(19), 178-204.

Bertrand, M. (2000). Los modos relacionales de las elites hispanoamericanas coloniales: enfoques y posturas. Anuario del IEHS, 15, 61-81.

Besio, N. (1939). Buenos Aires, puerto del Río de la Plata, capital de la Argentina. Estudio de su población (1536-1810). Buenos Aires: Talleres Gráficos Tuduri.

Borucki, A. (2011). The Slave Trade to the Río de la Plata, 1777-1812: Trans-Imperial Networks and Atlantic Warfare. Colonial Latin American Review, 20(1), 81-107. DOI: 10.1080/1060916 4.2011 .552550

Casarola, S. (2003). El núcleo de la élite colonial de Santiago de Guatemala: un bloqueo cohesivo. Araucaria. Revista Iberoamericana de Filosofía, Política y Humanidades, 5(10), 80-102.

Conti, V. E. y Gutiérrez, M. R. (2009). Empresarios de los Andes de la colonia a la independencia. Dos estudios de casos de Jujuy. América Latina en la Historia Económica, 16(2), 135. DOI: 10.18232/alhe.v16i2.419

Cutolo, V. O. (1978). Nuevo diccionario Biográfico Argentino (1750-1930). Buenos Aires: Elche.

Fernández, H. (1991). Aportes biogenealógicos para un padrón de habitantes del Río de la Plata. Buenos Aires: s. e.

Ferreiro, J. P. (2010). Aproximación analítico-estructural a los habitus nupciales, parentales y políticos de Jujuy durante el siglo XVII. Surandino Monográfico, segunda sección del Prohal Monográfico PROHAL Monográfico, 1(2). Recuperado de http://www.filo.uba.ar/contenidos/investigacion/ institutos/ravignani/prohal/SM_002_Articulos/002_Ferreiro.pdf

Gould, R. V. (1996). Patron-Client Ties, State Centralization, and the Whiskey Rebellion. American Journal of Sociology, 102(2), 400-429.

Granados, A. (2006). Las contratas en la ciudad de México. Redes sociales y negocios: el caso de Manuel Barrera (1800-1845). Política y Cultura, 26, 263-266.

Gribaudi, M. (ed.). (1998). Espaces, temporalités, stratifications: exercices sur les réseaux sociaux. Paris: Editions de l'Ecole des hautes études en sciences sociales.

Guerra, F. X. (1993). Modernidad e independencias: ensayos sobre las revoluciones hispánicas. México: Fondo de Cultura Económica,

Guerra, F. X. y Lempérière, A. (1998). Los espacios públicos en Iberoamérica: ambigüedades y problemas, siglos XVIII y XIX. México: Centro Francés de Estudios Mexicanos y Centroamericanos/Fondo de Cultura Económica.

Han, S. K. (2009). The Other Ride of Paul Revere: The Brokerage Role in the Making of the American Revolution. Mobilization: An International Quarterly, 14(2), 143-162. DOI: $10.17813 / \mathrm{ma}$ q.14.2.g360870167085210 
Hillmann, H. (2003). Factional Politics and Credit Networks in Revolutionary Vermont. Institute for Social and Economic Research and Policy [ISERP] Working Paper (03-02). DOI: 10.7916/d87h $1 \mathrm{rfp}$

Ibarra, A. (2007). Redes de circulación y redes de negociantes en el mercado interno novohispano: los mercaderes del Consulado de Guadalajara, 1791-1803. En A. Ibarra y G. del Valle (eds.), Redes sociales e instituciones comerciales en el imperio español, siglos XVII a XIX (pp. 161-186). México: Instituto de Investigaciones Dr. José María Luis Mora.

Jáuregui, C. (1989). Matrimonios de la Catedral de Buenos Aires, 1747-1823. Buenos Aires: Fuentes Históricas y Genealógicas Argentinas.

Johns, L. y Ville, S. (2012). Banking records, business and networks in colonial Sydney, 18171824. Australian Economic History Review, 52(2), 167-190. DOI: 10.1111/j.1467-8446.2012 $.00348 . x$

Johnson, L. L. y Seibert, S. (1979). Estimaciones de la población de Buenos Aires en 1744, 1778 y 1810. Desarrollo Económico, 19(73), 107-119. DOI: $10.2307 / 3466498$

Johnson, L. L., Socolow, S. M. y Seibert, S. (1980). Población y espacio en el Buenos Aires del siglo XVIII. Desarrollo Económico, 20(79), 329. DOI: 10.2307/3466434

Lin, N. (2001). Social capital: a theory of social structure and action. Nueva York: Cambridge University Press.

McDonald, J. F. y Moffitt, R. A. (1980). The Uses of Tobit Analysis. The Review of Economics and Statistics, 62(2), 318. DOI: 10.2307/1924766

Mitchell, J. C. (ed.). (1969). Social networks in urban situations: analyses of personal relationships in Central African towns. Manchester: Manchester University Press.

Molina, R. A. (2000). Diccionario biográfico de Buenos Aires (1580-1720). Buenos Aires: Academia Nacional de la Historia.

Morales, L. M. (2006). Redes y negocios en Puebla. Fortuna y mentalidad nobiliaria. Historia Caribe, 4(11), 73-85.

Moutoukias, Z. (1995). Narración y análisis en la observación de vínculos y dinámicas sociales: el concepto de red personal en la historia social y económica. En M. Bjerg y H. Otero (eds.), Inmigración y redes sociales en la Argentina moderna (pp. 63-81). Tandil: Centro de Estudios Migratorios Latinoamericanos.

Newman, M. E. J. (2005). A measure of betweenness centrality based on random walks. Social Networks, 27(1), 39-54. DOI: 10.1016/j.socnet.2004.11.009

Padgett, J. F. (1994). Marriage and elite structure in Renaissance Florence, 1282-1500 (pp. 1-30). Presentado en Social Science History Association Annual Meeting, Atlanta, Giorgia. Recuperado de http://home.uchicago.edu/jpadgett/papers/unpublished/maelite.pdf

Padgett, J. F. y McLean, P. D. (2006). Organizational Invention and Elite Transformation: The Birth of Partnership Systems in Renaissance Florence. American Journal of Sociology, 111(5), 1463-1568. DOI: $10.1086 / 498470$

Ponce, P. y Amadori, A. (2008). Redes sociales y ejercicio del poder en la América Hispana: consideraciones teóricas y propuestas de análisis. Revista Complutense de Historia de América, 34, 15-42.

Ramella, F. (1995). Por un uso fuerte del concepto de red en los estudios migratorios. En M. Bjerg y H. Otero (eds.), Inmigración y redes sociales en la Argentina moderna (pp. 9-21). Tandil: Centro de Estudios Migratorios Latinoamericanos. 
Río de la Plata (Virreinato). Consulado, Quesada, H. C. y Archivo General de la Nación (Argentina) (1936). Consulado de Buenos Aires: antecedentes, actas, documentos. Buenos Aires: Kraft.

Rodríguez, J. A. (1995). Análisis estructural y de redes. Madrid: Centro de Investigaciónes Sociológicas.

Rodríguez, J. C. (2015). La red del corsario francés Juan Chevallier y sus presas angloamericanas en el Caribe durante las guerras navales (1796-1808). América Latina en la Historia Económica, 22(1), 115. DOI: 10.18232/alhe.v22i1.601

Sánchez, E. (2007). Las incertidumbres del cambio: redes sociales y mercantiles de los hacendadoscomerciantes azucareros del centro de México (1800-1834). Historia Mexicana, 56(3), 919968.

Sandrín, M. E. (2013). La actividad económica de los asentistas de víveres de la Marina de Montevideo, 1770-1810. América Latina en la Historia Económica, 21(1), 92. DOI: 10.18232/alhe.v21i1.560

Scott, J. (2000). Social network analysis: a handbook (2a. edición). Londres: SAGE Publications.

Senor, M. S. (2005). El azar y la necesidad. Elite y elecciones matrimoniales en Buenos Aires 1776-1820. Las familias Azcuénaga y Andonaegui. Andes, 16, 1-18.

Udaondo, E. y Aráoz, G. (1945). Diccionario biográfico colonial argentino. Buenos Aires: Huarpes.

Valle, L. C. del. (2006). Dentro y fuera de la elite capitular: relaciones conflictivas en el Buenos Aires de fines del Siglo XVIII. Temas de Historia Argentina y Americana, 8, 61-76.

Valle, L. C. del. (2014). Los hijos del poder: de la élite capitular a la Revolución de Mayo: Buenos Aires 1776-1810. Buenos Aires: Prometeo Libros.

White, D. R. (2005). Teoría de la Cohesión Circular en el Matrimonio y las Redes Sociales. Empiria. Revista de metodología de ciencias sociales, 10, 37. DOI: 10.5944/empiria.10.2005.1043

Archivos

AGI Archivo General de Indias, Sevilla, España.

AGN Archivo General de la Nación, Buenos Aires, Argentina. 